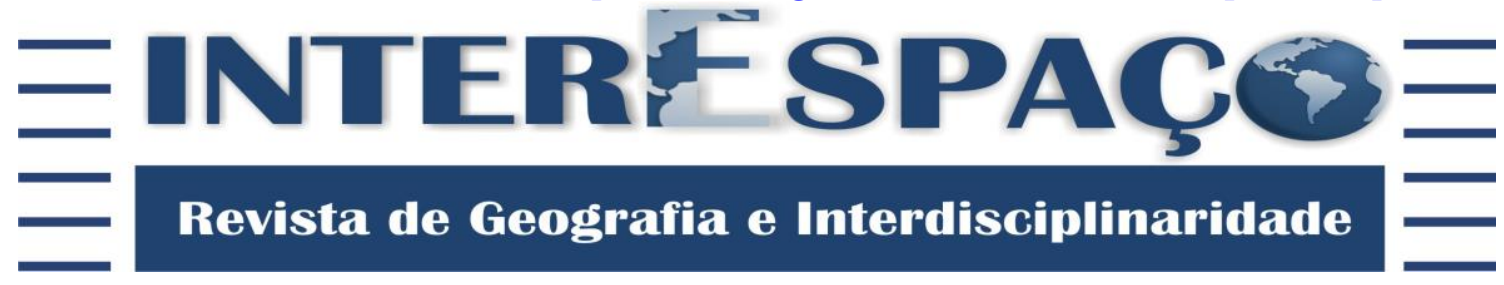

\section{GEOGRAFIA, GEOTECNOLOGIAS E AS NOVAS TENDÊNCIAS DA GEOINFORMAÇÃO: indicação de estudos realizados na região Nordeste}

\author{
Francisco Jonh Lennon Tavares da Silva \\ Graduado em Geografia pela Universidade Federal do Piauí - UFPI. \\ lennonufpi@hotmail.com
}

Dyego Freitas Rocha

Graduado em Geografia pela Universidade Federal do Rio Grande do Norte - UFRN. dyegofreitasrocha@gmail.com

\section{Cláudia Maria Sabóia de Aquino}

Doutora em Geografia pela Universidade Federal de Sergipe - UFS. Professora Adjunta do Departamento de Geografia da Universidade Federal do Piauí - UFPI. cmsaboia@gmail.com

\section{RESUMO}

A difusão do Geoprocessamento, do Sensoriamento Remoto e dos Sistemas de Informação Geográfica, abriu novas possibilidades de aplicação aos estudos geográficos. Nesse contexto e considerando o método bibliográfico como procedimento de análise, o artigo objetivou: (i) refletir sobre o impacto da postura geotecnológica sobre a meta básica da ciência geográfica, qual seja, explicar a organização do espaço, mediante abordagens e técnicas exitosas; (ii) indicar algumas tecnologias de análise espacial utilizadas no Brasil, evidenciando as novas tendências no contexto da Geoinformação e (iii) discutir a aplicação das Geotecnologias, indicando estudos realizados na região Nordeste. A partir do levantamento preliminar de estudos regionais, infere-se que as Geotecnologias têm grande potencial de aplicação nos estudos de Geografia Física.

Palavras-chave: Geoprocessamento; Sistemas de Informação Geográfica; Sensoriamento Remoto; Geoinformação.

\section{GEOGRAPHY, GEOTECHNOLOGIES AND THE NEW TRENDS IN}

GEOINFORMATION: indication of studies accomplished in the Northeast

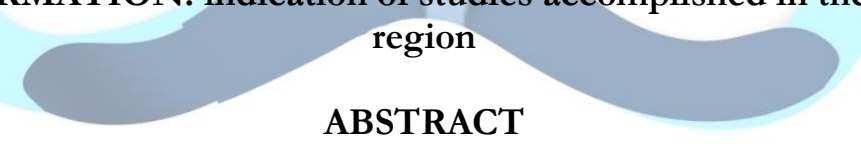

With the spread of Geoprocessing, Remote Sensing and Geographic Information Systems, new applications possibilities was opened for to the geographical studies. In this context and considering the bibliographical method as an analytical procedure, the papper aimed: (i) reflect on the impact of geotechnologic stance on the basic goal of geographical science, that is, explain the organization of space, through successful approaches and techniques; (ii) indicate some spatial analysis technologies used in Brazil, highlighting the new trends in the context of Geoinformation and (iii) discuss the application possibilities of Geotechnologies, indicating studies in the Northeast region. From the preliminary survey of regional studies, it infers that the Geotechnologies have great potential of application in Physical Geography studies. 
Geografia, geotecnologias e as novas tendências da geoinformação: indicação de estudos realizados na região Nordeste

Francisco Jonh Lennon Tavares da Silva; Dyego Freitas Rocha; Cláudia Maria Sabóia de Aquino

Keywords: Geoprocessing; Geographic Information Systems; Remote Sensing; Geoinformation.

\section{GEOGRAFÍA, GEOTECNOLOGÍAS Y LAS NUEVAS TENDENCIAS EN GEOINFORMACIÓN: indicación de estudios realizados en la región Nordeste}

\section{RESUMEN}

La difusión del Geoprocesamiento, Sensoriamento Remoto y Sistemas de Información Geográficas abrieron nuevas posibilidades de aplicación a los estudios geográficos. En este contexto y teniendo en cuenta el método bibliográfico como procedimiento analítico, el artículo tiene como objetivo: (i) reflexionar sobre el impacto de la postura geotecnológica en el objetivo básico de la ciencia geográfica, que es explicar la organización del espacio, a través de enfoques y técnicas exitosas; (ii) indicar algunas tecnologías de análisis espacial utilizadas en Brasil, destacando las nuevas tendencias en el contexto de la Geoinformación y (iii) discutir las posibilidades de aplicación de Geotecnologias, indicando estudios realizados en la región Nordeste. A partir del levantamiento preliminar de estudios regionales, se pudo inferir que las Geotecnologias tienen un gran potencial para su aplicación en los estudios de Geografía Física.

Palabras clave: Geoprocesamiento; Sistemas de Información Geográficas; Sensoriamento Remoto; Geoinformación.

\section{INTRODUÇÃO}

Ao longo da sua sistematização, a Geografia tem se caracterizado como a ciência que analisa a organização espacial dos fenômenos ambientais e socioeconômicos a partir de diferentes abordagens e técnicas. Para Rosa (2011, p. 276), “a análise espacial está obrigatoriamente associada à Geografia, correspondendo ao estudo da distribuição espacial de qualquer fenômeno, à procura de padrões espaciais".

Neste cenário e em consonância com o período técnico-científico-informacional, a fase atual dos estudos geográficos consagra-se pela aplicação generalizada das novas tecnologias de análise espacial, denominadas de Geotecnologias.

Concebidas por Kerski (2015) como uma das cinco tendências globais convergentes no seio da pesquisa geográfica, as Geotecnologias têm encontrado larga utilização na Geografia, no âmbito das suas várias subdisciplinas, permitindo mapear e analisar uma grande variedade de fenômenos, com uma rapidez e precisão sem precedentes.

Christofoletti (1999) destaca que, com a crescente demanda de estudos aplicados à análise ambiental, os procedimentos operacionais inerentes à modelagem espacial ganharam realce com as novas tecnologias para mapeamento digital e processamento de dados, visto que a manipulação de dados espaciais tornou-se parte essencial dos estudos de Geografia. 
Geografia, geotecnologias e as novas tendências da geoinformação: indicação de estudos realizados na região Nordeste

Francisco Jonh Lennon Tavares da Silva; Dyego Freitas Rocha; Cláudia Maria Sabóia de Aquino

Cumpre frisar que ainda são pouco discutidos os desdobramentos epistemológicos concernentes à postura geotecnológica no cerne da ciência geográfica (FERREIRA, 2006). Essa reflexão é necessária, pois o uso das Geotecnologias reclama e promove perspectivas teórico-metodológicas renovadas, mostrando-se, muitas vezes, incompatível com abordagens tradicionais (BAKER, 1986).

Nesse sentido, salienta-se que as Geotecnologias não portam em si o arcabouço teórico-conceitual apropriado às pesquisas, posto serem apenas ferramentas técnicas para o seu desenvolvimento. Assim sendo, cabe ao geógrafo explicitar os critérios que validam a aplicação destas ferramentas, destacando ainda o horizonte epistemológico no qual a problemática investigada em seu estudo melhor se enquadra.

Nessa conjuntura, considerando o método bibliográfico como procedimento de análise, o artigo objetivou: (i) refletir sobre o impacto da postura geotecnológica sobre a meta básica da ciência geográfica, qual seja, explicar a organização do espaço, mediante abordagens e técnicas exitosas; (ii) indicar algumas tecnologias de análise espacial utilizadas no Brasil, evidenciando as novas tendências no contexto da Geoinformação e (iii) discutir as possibilidades de aplicação das Geotecnologias, indicando estudos realizados na região Nordeste.

\section{GEOPROCESSAMENTO, SENSORIAMENTO REMOTO E SISTEMAS DE INFORMAÇÕES GEOGRÁFICAS}

Desde meados dos anos de 1960, período de maior efervescência dos pressupostos teórico-quantitativos da New Geography, até o início do século XXI, as técnicas de análise espacial têm sido aplicadas em diferentes vertentes da pesquisa geográfica, tanto nos estudos abrigados sob o termo geoambiental como nas pesquisas com enfoque geossocioeconômico (FERREIRA, 2006).

Nesse contexto, os avanços operacionais da ciência geográfica na explicação da organização do espaço devem muito ao aprimoramento das técnicas de coleta, tratamento e análise de dados georreferenciados. De fato, o uso das técnicas de Geoprocessamento e de Sensoriamento Remoto, integralizadas nos Sistemas de Informação Geográfica, tem permitido a análise de fenômenos cada vez mais complexos, antes inalcançáveis pela análise cartográfica tradicional.

Geoprocessamento é definido como uma tecnologia computacional com capacidade para integrar dados georreferenciados e transformá-los em informação 
Geografia, geotecnologias e as novas tendências da geoinformação: indicação de estudos realizados na região Nordeste

Francisco Jonh Lennon Tavares da Silva; Dyego Freitas Rocha; Cláudia Maria Sabóia de Aquino (ZAIDAN; XAVIER DA SILVA, 2007). Numa perspectiva mais pragmática, Albuquerque (2012, p. 35) complementa:

O Geoprocessamento apresenta-se como uma ferramenta que se mostra exitosa no desenvolvimento de ações que visam melhorar e adequar a gestão das análises sociais e ambientais, como também no desenvolvimento científico para o conhecimento da realidade, mesmo diante das mais diversas complexidades, tornando-se imprescindível para o ordenamento territorial.

$\mathrm{Na}$ apreciação de Rosa (2011), o Geoprocessamento abrange um conjunto de Geotecnologias voltadas para a coleta, o processamento e a manipulação de informações geograficamente referenciadas, destacando-se o Sensoriamento Remoto e o Sistema de Informações Geográficas (SIG), entre outras.

O Sensoriamento Remoto vem ganhando importância operacional em nível mundial, permitindo o levantamento de dados e informações com maior antecedência, com maior precisão e com menor custo quando comparadas com as técnicas tradicionais (IPPOLITI; EPIPHANIO; SHIMABUKURO, 1999).

A respeito das técnicas de Sensoriamento Remoto, Florenzano (2008) enfatiza que as imagens orbitais de alta resolução permitem a identificação e caracterização dos aspectos geoambientais, bem como proporcionam uma visão de conjunto e multitemporal de extensas áreas da superfície terrestre. Esta visão sinóptica do meio ambiente possibilita estudos regionais e integrados, evidenciando as paisagens em sua evolução, destacando os impactos ambientais de origem natural e antrópica.

Alimentados com os dados do Geoprocessamento e do Sensoriamento Remoto, os Sistemas de Informações Geográficas operacionalizam a manipulação e integração de grandes quantidades de informações (ZAIDAN; XAVIER DA SILVA, 2007).

Rosa (2005) afirma que um Sistema de Informações Geográficas funciona mediante a integração de cinco componentes básicos, quais sejam: computadores ou hardware, aplicativos computacionais ou software, dados, pessoas ou peopleware e método de trabalho (Figura 01). 
Geografia, geotecnologias e as novas tendências da geoinformação: indicação de estudos realizados na região Nordeste

Francisco Jonh Lennon Tavares da Silva; Dyego Freitas Rocha; Cláudia Maria Sabóia de Aquino

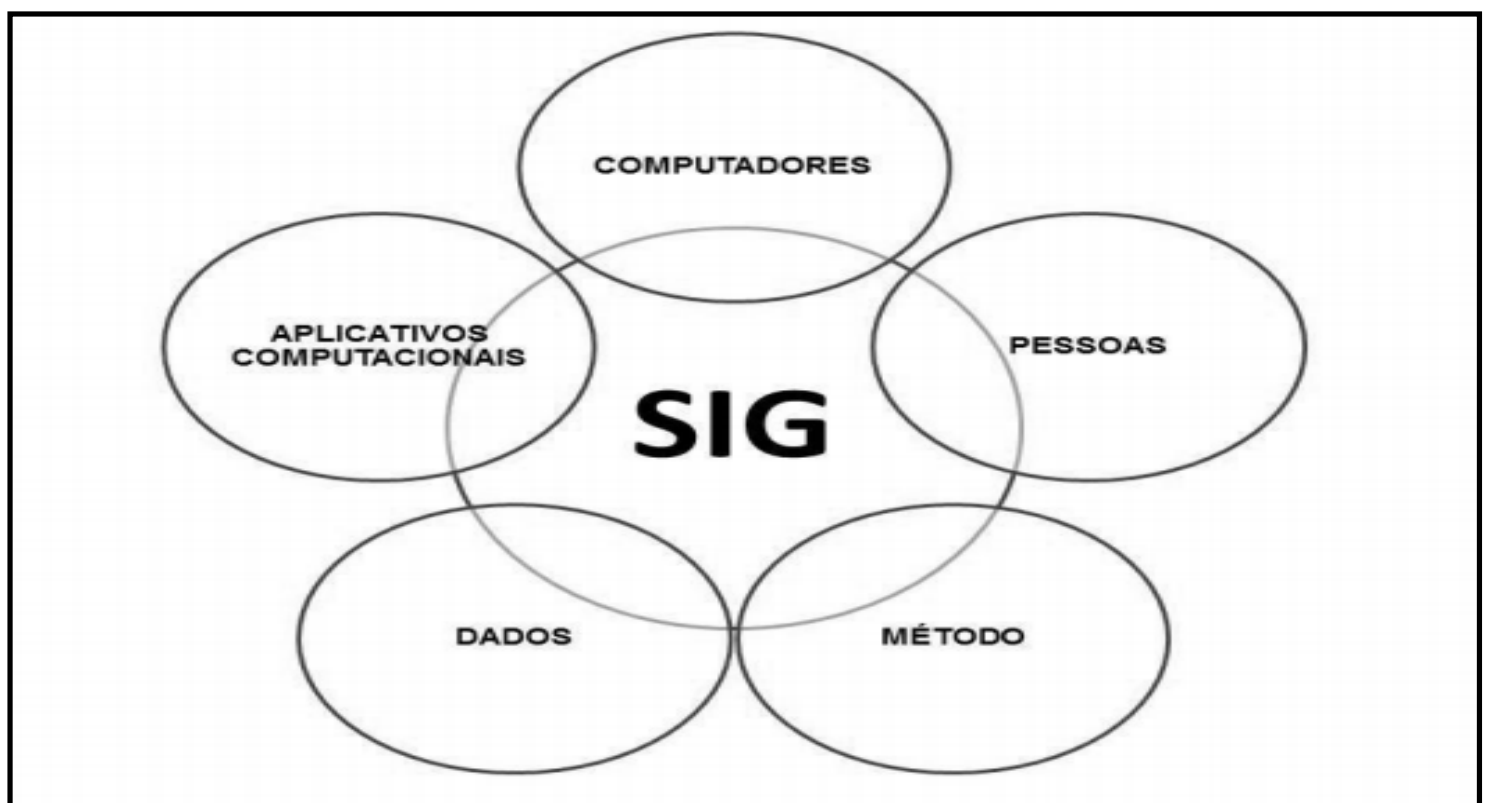

Figura 01 - Componentes de um Sistema de Informações Geográficas Fonte: Adaptado de ARAÚJO (2012).

É vasta a tipologia de programas de gerenciamento de dados, mapeamento digital e geoprocessamento disponíveis no mercado, cujas funcionalidades aprimoram-se a cada nova versão lançada (Quadro 01). Algumas das principais características destes e de outros softwares estão descritas na literatura (ROSA, 2005; AQUINO; VALLADARES, 2013). 
Geografia, geotecnologias e as novas tendências da geoinformação: indicação de estudos realizados na região Nordeste

Francisco Jonh Lennon Tavares da Silva; Dyego Freitas Rocha; Cláudia Maria Sabóia de Aquino

Quadro 01 - Alguns softwares de análise espacial utilizados no Brasil

\begin{tabular}{|c|c|}
\hline Programas & Funcionalidades \\
\hline ArcGIS & $\begin{array}{l}\text { Geoprocessamento. Modelagem Digital do Terreno. Análise } \\
\text { Geoestatística. }\end{array}$ \\
\hline QGIS & $\begin{array}{l}\text { Geoprocessamento. Modelagem Digital do Terreno. Análise } \\
\text { Geoestatística. }\end{array}$ \\
\hline Global Mapper & $\begin{array}{l}\text { Geoprocessamento. Modelagem Digital do Terreno. Análise } \\
\text { Geoestatística. Exportação de dados. }\end{array}$ \\
\hline Spring & Geoprocessamento. Modelagem numérica de terreno. \\
\hline gvSIG & Geoprocessamento. \\
\hline AutoCAD Map 3D & Gerenciamento de dados espaciais. Acesso a dados CAD. \\
\hline PostgreSQL (PostGIS) & Gerenciamento de dados espaciais. \\
\hline Saga & Geoprocessamento. \\
\hline Kosmo & Geoprocessamento. \\
\hline Surfer & Geoprocessamento. Modelagem digital de elevação. \\
\hline SAS.GIS & Geoprocessamento. \\
\hline Idrisi & $\begin{array}{l}\text { Geoprocessamento. Classificação por segmentação de } \\
\text { imagens. Modelagem por detecção de mudanças. }\end{array}$ \\
\hline Envi & $\begin{array}{l}\text { Geoprocessamento. Classificações supervisionadas e não- } \\
\text { supervisionadas. }\end{array}$ \\
\hline TerraView/SIG & Gerenciamento de dados espaciais. Geoprocessamento. \\
\hline ERDAS imagine & Geoprocessamento. Ortorretificação de imagens. \\
\hline
\end{tabular}

Fonte: ROSA (2005); AQUINO; VALLADARES (2013).

A despeito dos avanços, deve-se assinalar que compreender a organização do espaço geográfico a partir do uso das Geotecnologias não significa deixar este entendimento à mercê das novas ferramentas. Logo, compete ao pesquisador reconhecer e ponderar sobre as perspectivas e nuanças teórico-metodológicas a partir das quais a sua ciência tem sido praticada ao longo das décadas. Nessa perspectiva, Florenzano (2008, p. 126) comenta que:

Na aplicação das geotecnologias, é fundamental [...] não esquecer a importância do conhecimento teórico das áreas temáticas objeto de estudo. Sem esse conhecimento, tanto a exploração das geotecnologias quanto a análise e interpretação dos resultados serão parciais, o que poderá levar a conclusões inconsistentes ou erradas.

Nesse mesmo viés de reflexão, Araújo (2012, p. 64) tece as seguintes considerações acerca da aplicação das Geotecnologias aos estudos geográficos: 
Geografia, geotecnologias e as novas tendências da geoinformação: indicação de estudos realizados na região Nordeste

Francisco Jonh Lennon Tavares da Silva; Dyego Freitas Rocha; Cláudia Maria Sabóia de Aquino

A utilização de SIGs pela Geografia vai além da proposição de novas técnicas ou de novos métodos, passa pelo desenvolvimento de novas teorias e de novos enquadramentos filosóficos. Abrem-se novos horizontes para o entendimento da mecânica das relações entre a Sociedade e o uso que ela faz do espaço que ocupa. O contexto atual é propício para o desenvolvimento desta nova mentalidade na Geografia.

Destaca-se que o uso das Geotecnologias tem despertado maior atenção dos pesquisadores quando da escolha das suas abordagens teórico-metodológicas. É evidente, por exemplo, a busca de abordagens integrativas que promovam uma aproximação entre os princípios e possibilidades da técnica com os mecanismos regentes da dinâmica do espaço geográfico.

Aos geógrafos, em específico, abre-se um conjunto muito promissor de possibilidades, tanto na aplicação das novas tecnologias de análise espacial (viés empírico) como na labuta de se refletir sobre os seus desdobramentos epistemológicos (viés teórico). A amarração destes dois vieses coloca-se, portanto, como tarefa inadiável para as novas gerações de geógrafos-pesquisadores.

\section{TECNOLOGIAS EMERGENTES E TENDÊNCIAS ATUAIS DA GEOINFORMAÇÃO: VANT, LIDAR E SIG-WEB}

Como salientado, o avanço decorrente da análise do espaço tem sido subsidiado por importantes ferramentas dentro das Geotecnologias, as quais geram ricas informações geoespaciais, análises temporais, diagnósticos e prognósticos.

O desenvolvimento de plataformas e sensores para a aquisição de informação espacial, com vistas à atualização de bases de dados cartográficos, teve um grande avanço a partir do século XXI, através de modernas etapas de processamento digital (LUZ; ANTUNES, 2015).

Nesse contexto, os Veículos Aéreos Não Tripulados (VANTs) vêm conquistando a preferência dos profissionais que trabalham com a aplicação de Geotecnologias, em vista também do custo relativamente baixo quando comparado aos levantamentos aerofotogramétricos tradicionais (ALVES JÚNIOR, 2015).

A tecnologia VANT é composta por uma aeronave, projetada para operar sem piloto a bordo, configurando-se, assim, como um Sistema de Veículo Aéreo Não Tripulado (SISVANT). A principal característica de um SISVANT é a possibilidade de portar sensores (câmera fotográfica digital) e equipamentos (receptores GNSS) e, com isso, extrair as informações espaciais de interesse (LUZ; ANTUNES, 2015). 
Geografia, geotecnologias e as novas tendências da geoinformação: indicação de estudos realizados na região Nordeste

Francisco Jonh Lennon Tavares da Silva; Dyego Freitas Rocha; Cláudia Maria Sabóia de Aquino

Metodologicamente, os estudos apoiados em VANTs orientam-se, em linhas gerais, pelas seguintes etapas: (i) delimitação e análise preliminar da área de estudo; (ii) planejamento do voo, considerando, dentre outros fatores, a altura do voo e as características da câmera utilizada; (iii) aquisição dos dados e imagens pelo VANT; (iv) processamento dos dados oriundos da coleta feita pelo VANT; (v) atualização das bases geocartográficas, mediante etapa de fotointerpretação e (vi) validação dos produtos cartográficos gerados, considerando a qualidade temática daquilo que se pretende representar da verdade terrestre (Figura 02).

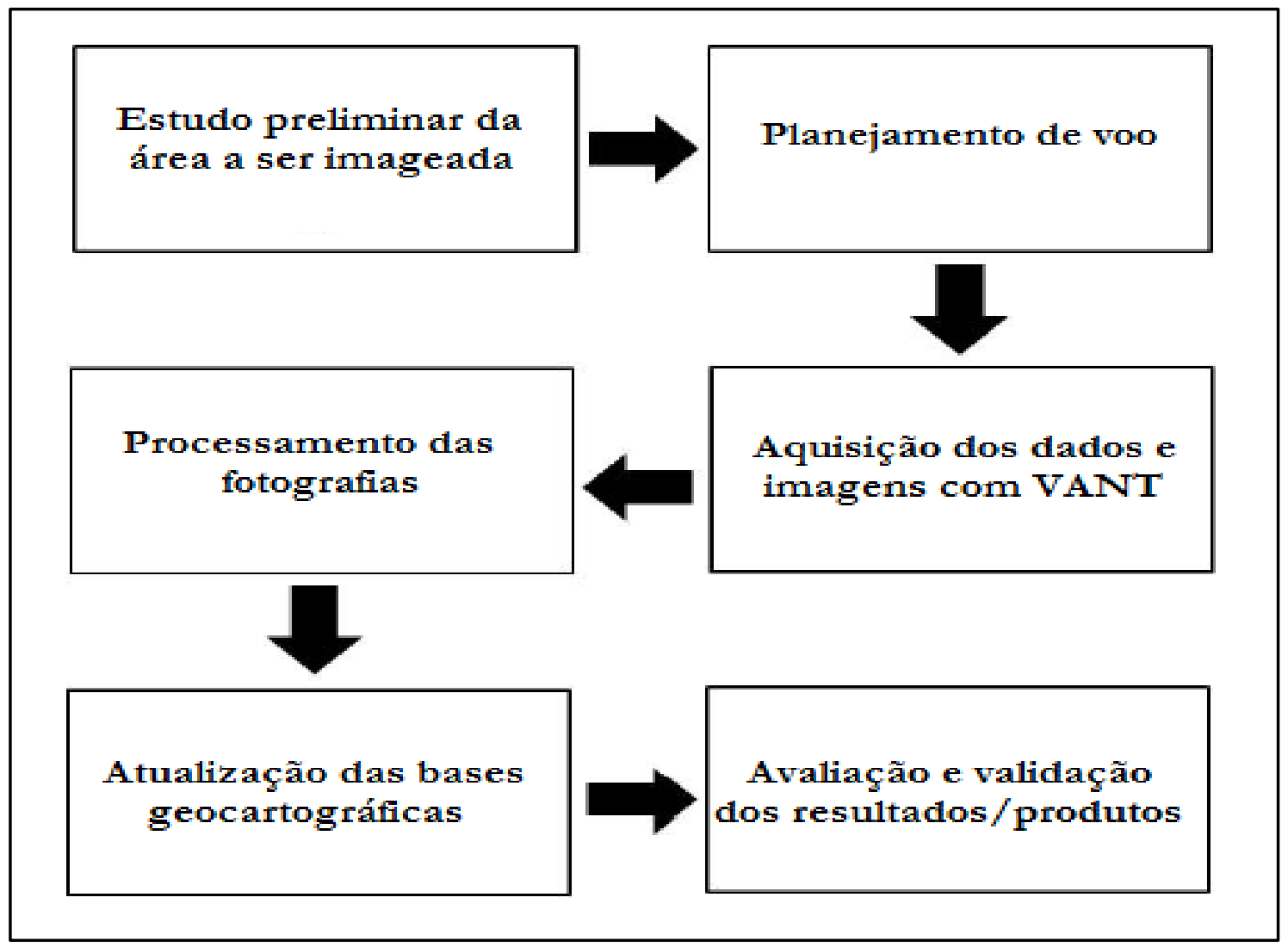

Figura 02 - Fluxograma metodológico hipotético de estudo baseado em VANT Fonte: Adaptado de LUZ; ANTUNES (2015).

No âmbito dos aprimoramentos do Sensoriamento Remoto, especificamente no que se refere às técnicas de representação da superfície terrestre por meio da representação digital do relevo, o LIDAR (Light Detection and Ranging) tem se salientando como uma das alternativas mais eficientes na obtenção de modelos digitais de terreno (MDT), curvas de nível, modelos digitais de elevação (MDE), dentre outros levantamentos de precisão (AMORIM; SILVA, 2012).

Conforme apontam Galvanin e Dal Poz (2013), o princípio básico do sistema LIDAR consiste na utilização de um feixe de laser emitido a partir de um espelho de 
Geografia, geotecnologias e as novas tendências da geoinformação: indicação de estudos realizados na região Nordeste

Francisco Jonh Lennon Tavares da Silva; Dyego Freitas Rocha; Cláudia Maria Sabóia de Aquino varredura, com foco nos objetos investigados. Este feixe é refletido ao atingir a superfície dos objetos, redirecionando um eco ao sistema. Este sistema encarrega-se então de registrar o tempo decorrido entre a emissão e a captação do eco, permitindo a obtenção da distância entre o sensor e o objeto focalizado (Figura 03).

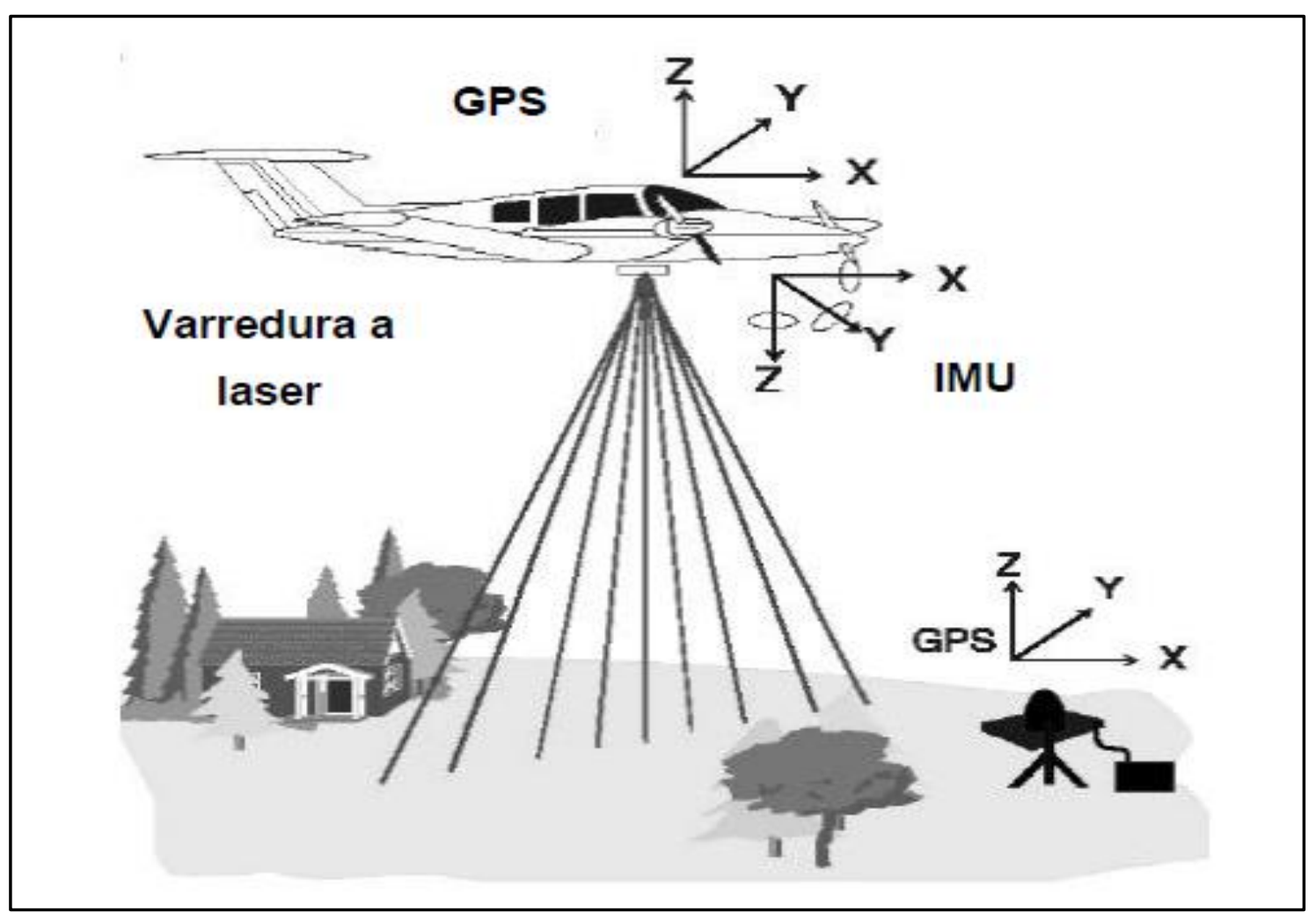

Figura 03 - Modelo hipotético de sistema de varredura a laser

Fonte: Adaptado de GALVANIN; DAL POZ (2013).

Como mostra a ilustração, o sistema aerotransportado de varredura a laser LIDAR funciona pela integração de equipamentos auxiliares, tais como o Sistema de Posicionamento Global (GPS) e Sistema de Medição Inercial (IMU). O GPS tem a finalidade de fornecer a posição instantânea do sensor durante o processo de coleta dos dados. Um receptor GPS é instalado no interior da aeronave para executar o rastreio cinemático. O segundo receptor GPS é posicionado no terreno, sobre um ponto de coordenadas conhecidas, realizando o rastreando estático. Por sua vez, o IMU fornece os ângulos de altitude durante a aquisição dos dados (SCHIMALESKY; CENTENO, 2008).

Cita-se o Projeto Pernambuco Tridimensional (PE 3D), destinado a gerar base de dados espaciais de alta definição para todo o território do Estado de Pernambuco, por meio do sistema de varredura a laser LIDAR (CIRILO et al., 2014).

O panorama de crescente disponibilização de bases cartográficas na rede mundial de computadores (World Wide Web) tornou-se possível graças aos avanços da tecnologia da 
Geografia, geotecnologias e as novas tendências da geoinformação: indicação de estudos realizados na região Nordeste

Francisco Jonh Lennon Tavares da Silva; Dyego Freitas Rocha; Cláudia Maria Sabóia de Aquino informação, permitindo o acesso aos produtos do Geoprocessamento por parte de usuários comuns, através de softwares livres. Neste ínterim, destaca-se o SIG-WEB, uma aplicação geotecnológica que usa a Internet como meio principal de acesso à Geoinformação (ALBUQUERQUE et al., 2012).

No contexto da nova geração de softwares livres, o SIG-WEB caracteriza-se como uma plataforma virtual que permite o armazenamento, análise, manipulação e gerenciamento de dados geoespaciais. Assim, é possível obter dados geoespaciais com maior rapidez, gerando resultados mais precisos e num lapso de tempo reduzido. Informações que antes ficavam concentradas nos grandes bancos de dados das instituições oficiais de pesquisa, tais como IBGE, passaram a ser disponibilizadas aos usuários de forma descentralizada.

No conjunto das características dessa nova tendência da Geoinformação, cita-se que os servidores de mapas permitem aos usuários uma ampla interação com as informações espaciais disponibilizadas. Através do servidor de mapas, o usuário pode acessar as informações no formato original e realizar consultas em diferentes níveis de complexidade. Salienta-se que o acesso às informações deve ser dinâmico para facilitar a forma de interpretação e análise dos dados pelo usuário (PIMENTA et al., 2012).

Aplicações SIG-WEB têm recebido muito destaque nos últimos anos, pois a informação geográfica pode ser visualizada e manipulada em diferentes locais, por diferentes perfis de usuários, através da Internet (SCHIMIGUEL; BARANAUSKAS; MEDEIROS, 2005). Exemplos de aplicações SIG em ambiente Web são o i3Geo e o Ceará em Mapas Interativos.

Desenvolvido pelo Ministério do Meio Ambiente (MMA) a partir de um conjunto de softwares livres, tais como o Mapserver, o i3Geo tem por foco principal a disponibilização de dados geográficos e ferramentas de navegação, compartilhamento e geração de mapas, dentre outras informações geoespaciais produzidas pelo governo federal (Figura 04). 
Geografia, geotecnologias e as novas tendências da geoinformação: indicação de estudos realizados na região Nordeste

Francisco Jonh Lennon Tavares da Silva; Dyego Freitas Rocha; Cláudia Maria Sabóia de Aquino

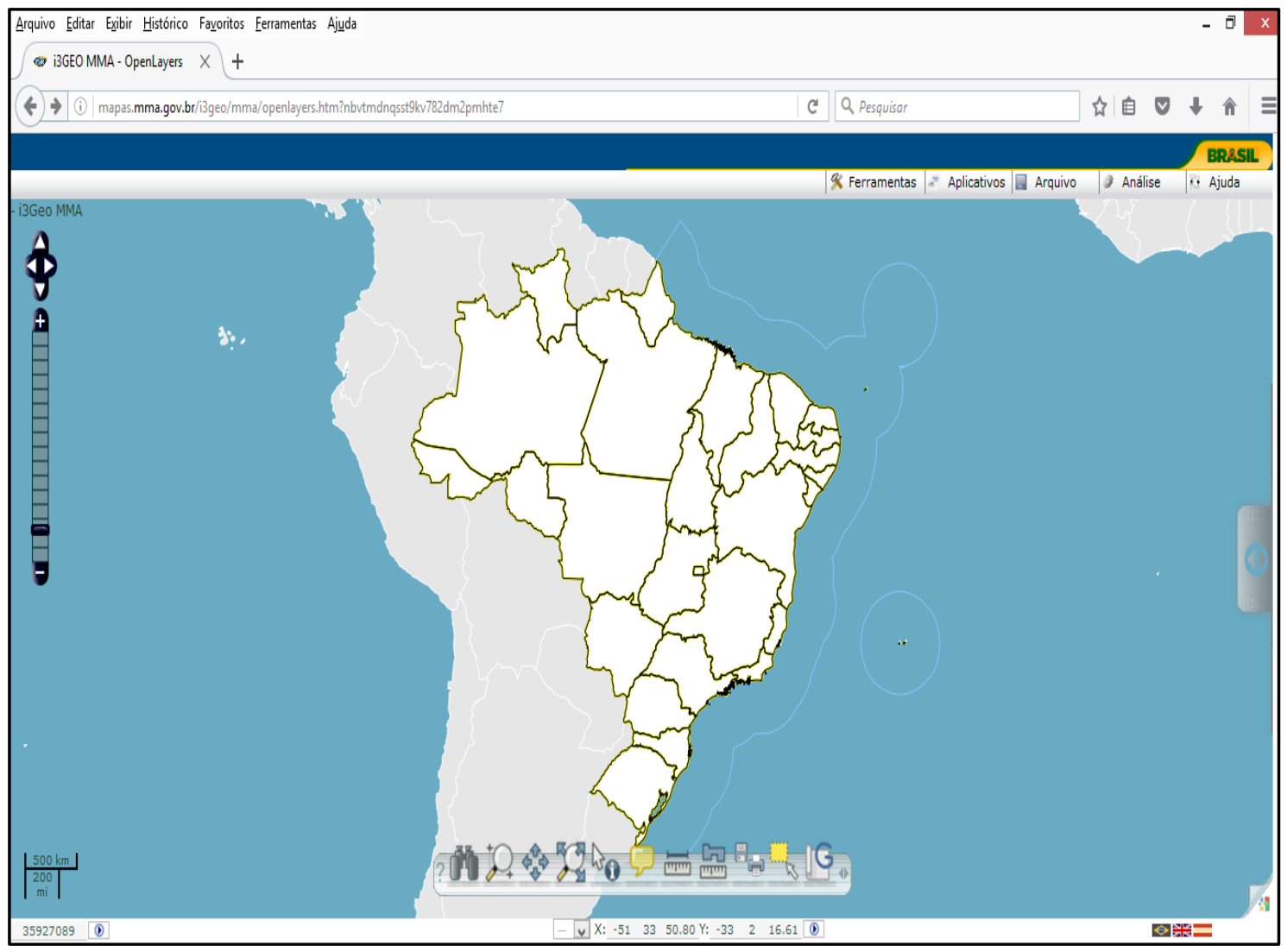

Figura 04 - Interface inicial do SIG-WEB i3Geo

Fonte: MMA (2016).

No Brasil, o i3Geo integra o portal de geoserviços da Infraestrutura Nacional de Dados Espaciais (INDE), customizando o acesso a dados, metadados e informações geoespaciais através de serviços na Internet. Por ter uma interface amigável e de fácil manuseio, o i3Geo permite inúmeras possibilidades de uso, entre elas a utilização no ensino de Geografia (GIROTTO; PELEGRINA, 2010).

Produto da iniciativa do Instituto de Pesquisa e Estratégia Econômica do Ceará (IPECE), o SIG-WEB Ceará em Mapas Interativos constitui-se em um típico Sistema de Informações Georreferenciadas para Internet.

Baseado, dentre outros, no desenho do software i3Geo, o Ceará em Mapas Interativos oferece consultas e análises utilizando dados georreferenciados, tais como: limites e regionalizações; imagens de satélite; ortofotos; mapas de indicadores socioeconômicos; mapas de áreas degradadas; mapas de unidades fitoecológicas; mapas de unidades geoambientais; mapas dos tipos climáticos; mapas dos recursos hídricos, entre outros (ALBUQUERQUE et al. 2012; IPECE, 2016). A Figura 05 evidencia a interface do SIG-WEB em epígrafe. 
Geografia, geotecnologias e as novas tendências da geoinformação: indicação de estudos realizados na região Nordeste

Francisco Jonh Lennon Tavares da Silva; Dyego Freitas Rocha; Cláudia Maria Sabóia de Aquino

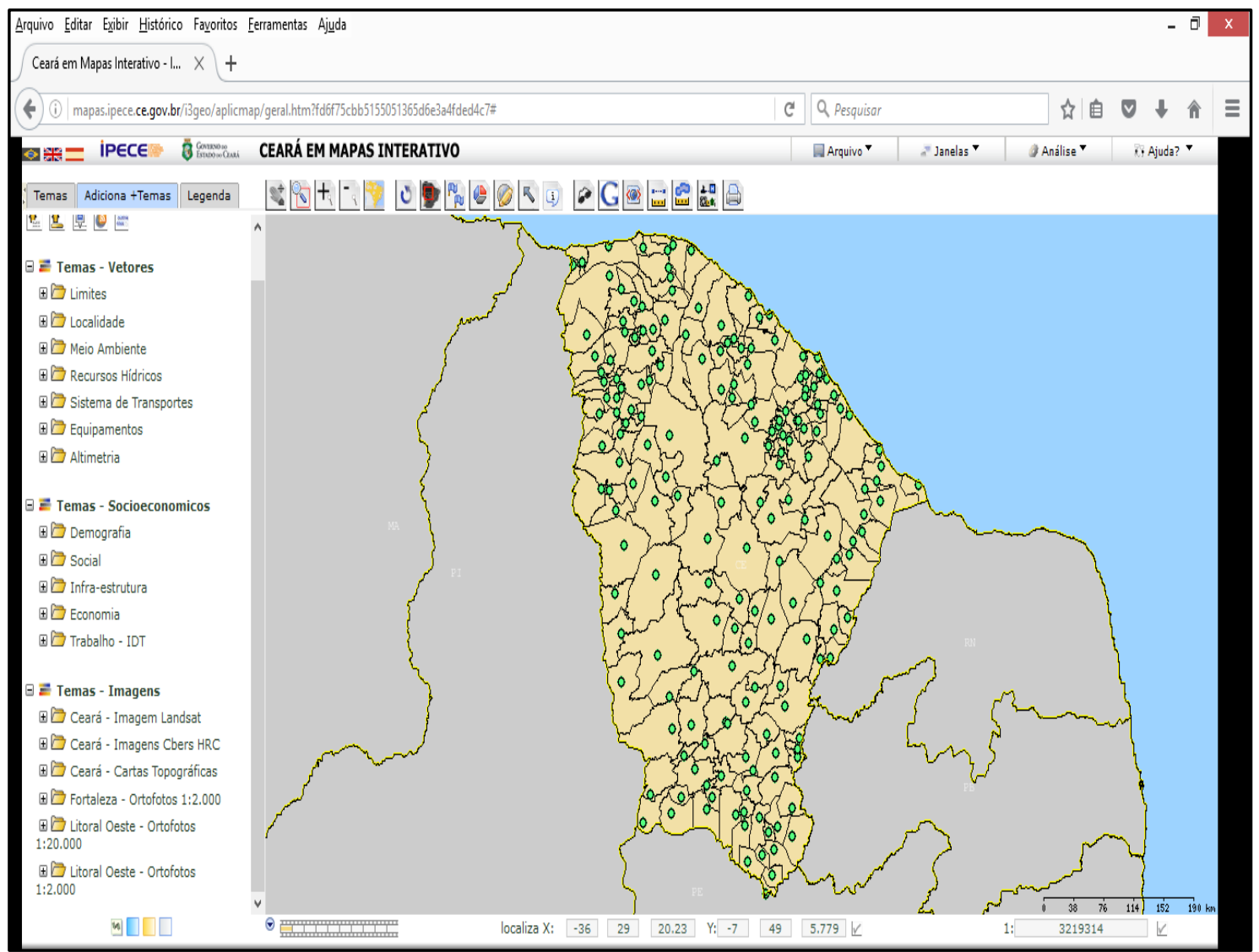

Figura 05 - Interface inicial do SIG-WEB Ceará em Mapas Interativos

Fonte: IPECE (2016).

Convém destacar a relevância dessa ferramenta no ensino de Geografia. Neste prisma, Albuquerque et al. (2012) concordam que o uso ponderado do SIG-WEB Ceará em Mapas Interativos torna o processo de ensino-aprendizagem mais dinâmico e atrativo, despertando o interesse dos alunos na busca e aquisição de informações e/ou dados atualizados.

\section{GEOTECNOLOGIAS E SUAS APLICAÇÕES TEMÁTICAS: indicação de estudos} realizados na Região Nordeste

As tecnologias atuais voltadas para o estudo do espaço geográfico têm mostrado soluções eficazes para dinamizar o processo de gestão e a tomada de decisões futuras em relação à lógica de organização do espaço. Para as pesquisas em Geografia, o Geoprocessamento, os Sistemas de Informação Geográfica, o Sensoriamento Remoto e demais tecnologias emergentes são instrumentos exitosos que permitem uma melhor interpretação e representação dos fenômenos que se manifestam no espaço geográfico, constituindo-se em ferramentas fundamentais para fins de ordenamento territorial, análise e 
Geografia, geotecnologias e as novas tendências da geoinformação: indicação de estudos realizados na região Nordeste

Francisco Jonh Lennon Tavares da Silva; Dyego Freitas Rocha; Cláudia Maria Sabóia de Aquino monitoramento ambiental (AQUINO; VALLADARES, 2013). São apresentadas a seguir algumas das aplicações temáticas em Geotecnologias, indicando-se estudos realizados na região Nordeste.

\section{Utilização de geotecnologias nos estudos sobre degradação ambiental e desertificação}

O combate à desertificação e seus efeitos ambientais têm preenchido a agenda de inúmeros pesquisadores, no Brasil e no exterior. Na região Nordeste, o tema destaca-se como uma das questões mais importantes na atualidade, configurando-se como um dos grandes problemas ambientais. Nesse contexto, o geoprocessamento, o sensoriamento remoto e os SIGs constituem suporte técnico crucial para o monitoramento do fenômeno da degradação/desertificação, na perspectiva em que operacionalizam o processo de aquisição e análise de informações, possibilitando a estruturação de cenários tendenciais e a delimitação de áreas susceptíveis ao fenômeno. Na região Nordeste, citam-se os estudos sobre o tema realizados a partir da aplicação das geotecnologias (Quadro 02). 
Geografia, geotecnologias e as novas tendências da geoinformação: indicação de estudos realizados na região Nordeste

Francisco Jonh Lennon Tavares da Silva; Dyego Freitas Rocha; Cláudia Maria Sabóia de Aquino

Quadro 02 - Estudos sobre degradação/desertificação com suporte de geotecnologias

\begin{tabular}{|c|c|c|}
\hline Autor (es) & Título/Recorte espacial & $\begin{array}{l}\text { Geotecnolo } \\
\text { gias } \\
\text { utilizadas }\end{array}$ \\
\hline $\begin{array}{l}\text { Nascimento } \\
\text { (2006). }\end{array}$ & $\begin{array}{l}\text { Degradação ambiental e desertificação no nordeste } \\
\text { brasileiro: o contexto da bacia hidrográfica do rio } \\
\text { Acaraú/Ceará. }\end{array}$ & $\begin{array}{l}\text { AutoCAD } \\
\text { Map; } \\
\text { SPRING 4x; } \\
\text { Global } \\
\text { Mapper. }\end{array}$ \\
\hline $\begin{array}{l}\text { Bezerra et al. } \\
\text { (2011). }\end{array}$ & $\begin{array}{l}\text { Utilização de geotecnologias na determinação de áreas } \\
\text { susceptíveis à desertificação no estado do Rio Grande } \\
\text { do Norte. }\end{array}$ & $\begin{array}{l}\text { SPRING } \\
5.1 ; \text { ArcGIS } \\
9.3\end{array}$ \\
\hline $\begin{array}{l}\text { Silva; Melo; } \\
\text { Galvíncio } \\
\text { (2011). }\end{array}$ & $\begin{array}{l}\text { Identificação das áreas susceptíveis a processos de } \\
\text { desertificação no médio trecho da bacia do } \\
\text { Ipojuca/PE através do mapeamento do estresse } \\
\text { hídrico da vegetação e da estimativa do índice de } \\
\text { aridez. }\end{array}$ & $\begin{array}{l}\text { ERDAS } \\
\text { imagine } 9.3 \\
\text { ArcGIS } 9.3\end{array}$ \\
\hline $\begin{array}{l}\text { Aquino; } \\
\text { Almeida; } \\
\text { Oliveira } \\
\text { (2012). }\end{array}$ & $\begin{array}{l}\text { Aspectos socioambientais do núcleo de desertificação } \\
\text { de São Raimundo Nonato/Piauí. }\end{array}$ & IDRISI 3.2 \\
\hline $\begin{array}{l}\text { Sá et al. } \\
(2014) \text {. }\end{array}$ & $\begin{array}{l}\text { Mapeamento da desertificação da mesorregião Sul do } \\
\text { Ceará com base na cobertura vegetal e nas classes de } \\
\text { solos. }\end{array}$ & ArcGIS 10.2 \\
\hline Santos (2015). & $\begin{array}{l}\text { Mapeamento das unidades geoambientais e estudo do } \\
\text { risco de degradação/desertificação nos municípios de } \\
\text { Castelo do Piauí e Juazeiro do Piauí. }\end{array}$ & ArcGIS 10 \\
\hline
\end{tabular}

Fonte: Elaboração dos autores (2016).

\section{Utilização de geotecnologias no planejamento ambiental e gestão de bacias hidrográficas}

A utilização das novas tecnologias de análise espacial proporciona a observação dos sistemas fluviais como um todo integrado, considerando suas transformações e ajudando a evidenciar os impactos causados pela ação humana. Depreende-se, portando, que a aplicação de geotecnologias aos estudos de bacias hidrográficas facilitam os programas de planejamento ambiental e gestão mais eficiente dos recursos hídricos, tendo em vista que as informações estruturadas em banco de dados podem ser avaliadas de maneira instantânea e sistemática. Os estudos indicados a seguir validam o emprego dessas ferramentas à temática em destaque (Quadro 03). 
Geografia, geotecnologias e as novas tendências da geoinformação: indicação de estudos realizados na região Nordeste

Francisco Jonh Lennon Tavares da Silva; Dyego Freitas Rocha; Cláudia Maria Sabóia de Aquino

Quadro 03 - Estudos em bacias hidrográficas com suporte de geotecnologias

\begin{tabular}{|c|c|c|}
\hline Autor (es) & Título/Recorte espacial & $\begin{array}{l}\text { Geotecnolo } \\
\text { gias } \\
\text { utilizadas }\end{array}$ \\
\hline $\begin{array}{l}\text { Silva et al. } \\
\text { (2012). }\end{array}$ & $\begin{array}{l}\text { Delimitação de geoambientes numa bacia hidrográfica } \\
\text { na zona da mata de Pernambuco. }\end{array}$ & ArcGIS 9.3 \\
\hline $\begin{array}{l}\text { Gomes et al. } \\
\text { (2013). }\end{array}$ & $\begin{array}{l}\text { Geotecnologias aplicadas ao diagnóstico geoambiental } \\
\text { da bacia hidrográfica do rio Jaibaras no semiárido } \\
\text { cearense. }\end{array}$ & $\begin{array}{l}\text { SPRING } \\
4.3 .3 \text { e } 5.1 .3 \\
\text { ArcGIS } 9.3\end{array}$ \\
\hline $\begin{array}{l}\text { Queiroz; } \\
\text { Sales; Silva } \\
\quad(2014)\end{array}$ & $\begin{array}{l}\text { Indicadores morfométricos como subsidio ao } \\
\text { planejamento ambiental em um setor do médio curso } \\
\text { da bacia hidrográfica do rio Pacoti/CE. }\end{array}$ & $\begin{array}{c}\text { ArcGIS 9.1; } \\
\text { GvSig 1.9; } \\
\text { Google } \\
\text { Earth }\end{array}$ \\
\hline $\begin{array}{l}\text { Britto et al. } \\
\text { (2014). }\end{array}$ & $\begin{array}{l}\text { Sustentabilidade hídrica da sub-bacia do rio } \\
\text { Sangradouro, Sergipe. }\end{array}$ & ArcGIS 10x \\
\hline $\begin{array}{l}\text { Costa; } \\
\text { Oliveira } \\
(2015)\end{array}$ & $\begin{array}{l}\text { Os sistemas ambientais e a análise ambiental no } \\
\text { contexto semiárido: o caso da sub-bacia hidrográfica } \\
\text { do riacho Santa Rosa. }\end{array}$ & ArcGIS 10 \\
\hline $\begin{array}{l}\text { Albuquerque; } \\
\text { Souza (2016). }\end{array}$ & $\begin{array}{l}\text { Condições ambientais e socioeconômicas nas bacias } \\
\text { hidrográficas costeiras do setor leste metropolitano de } \\
\text { Fortaleza, estado do Ceará. }\end{array}$ & $\begin{array}{c}\text { QGIS 1.6.0; } \\
\text { SPRING } \\
\text { 5.2.7; } \\
\text { ArcGIS 9.3; } \\
\text { PostgreSQL } \\
\text { 9.0.4-1 }\end{array}$ \\
\hline
\end{tabular}

Fonte: Elaboração dos autores (2016).

Utilização de geotecnologias nos estudos sobre uso/ocupação e cobertura da terra e impactos associados

$\mathrm{Na}$ literatura geográfica contemporânea pode-se visualizar que uma das mais recorrentes aplicações temáticas das geotecnologias se realiza no levantamento das tipologias e tendências no uso e ocupação da terra - análises estas imprescindíveis para a compreensão das formas pelas quais o espaço geográfico está sendo ocupado. Assim, vale mencionar que essa modalidade de mapeamento, quando respaldada nas atuais ferramentas de análise espacial, fornece importantes subsídios ao planejamento ambiental, na perspectiva de mitigar o intenso processo de uso e ocupação em áreas de reconhecida fragilidade e vulnerabilidade socioambiental. Dessa maneira e considerando o crivo da perspectiva geográfica aplicada ao tratamento das questões ambientais, contata-se que as pesquisas sobre o tema em tela tomam como pressuposto basilar o entendimento integrado das inter-relações entre os sistemas naturais e socioeconômicos (Quadro 04). 
Geografia, geotecnologias e as novas tendências da geoinformação: indicação de estudos realizados na região Nordeste

Francisco Jonh Lennon Tavares da Silva; Dyego Freitas Rocha; Cláudia Maria Sabóia de Aquino

Quadro 04 - Estudos sobre uso e ocupação da terra com suporte de geotecnologias

\begin{tabular}{|c|c|c|}
\hline Autor (es) & Título/Recorte espacial & $\begin{array}{l}\text { Geotecnologias } \\
\text { utilizadas }\end{array}$ \\
\hline $\begin{array}{l}\text { Barbosa } \\
\text { Neto et al. } \\
\text { (2011). }\end{array}$ & $\begin{array}{l}\text { Uso da terra na bacia hidrográfica do rio Natuba, } \\
\text { Pernambuco. }\end{array}$ & $\begin{array}{l}\text { ERDAS imagine } \\
9.3 \text {; ArcGIS } 9.3\end{array}$ \\
\hline $\begin{array}{l}\text { Melo; Lima } \\
\text { (2012). }\end{array}$ & $\begin{array}{l}\text { Uso da terra, vulnerabilidade e subsídios ao } \\
\text { ordenamento territorial em microbacia. }\end{array}$ & SPRING 4.3 \\
\hline $\begin{array}{l}\text { Amorim; } \\
\text { Oliveira } \\
\text { (2013). }\end{array}$ & $\begin{array}{l}\text { Zoneamento ambiental, subsídio ao planejamento no } \\
\text { uso e ocupação das terras da costa do descobrimento. }\end{array}$ & ArcGIS 9.3 \\
\hline $\begin{array}{l}\text { Cardoso; } \\
\text { Aquino } \\
\text { (2013). }\end{array}$ & $\begin{array}{l}\text { Análise dos usos e cobertura das terras das } \\
\text { microbacias hidrográficas do riacho do Roncador - } \\
\text { Timon (MA): subsídios ao planejamento ambiental. }\end{array}$ & ArcGIS 9.3 \\
\hline $\begin{array}{l}\text { Cabral; } \\
\text { Silva; Girão } \\
\quad(2014) .\end{array}$ & $\begin{array}{l}\text { Impactos ambientais derivados do uso e ocupação da } \\
\text { linha de costa em trechos das praias de Pau Amarelo e } \\
\text { Maria Farinha - município de Paulista/PE: estudo } \\
\text { Preliminar. }\end{array}$ & $\begin{array}{l}\text { ArcGIS 10.1; } \\
\text { Google Earth }\end{array}$ \\
\hline $\begin{array}{l}\text { Sousa; } \\
\text { Moura; } \\
\text { Silva (2015). }\end{array}$ & $\begin{array}{l}\text { Diagnóstico socioambiental da ocupação desordenada } \\
\text { do campo de dunas na comunidade Iguape/Aquiraz- } \\
\text { CE. }\end{array}$ & Global Mapper \\
\hline
\end{tabular}

Fonte: Elaboração dos autores (2016).

\section{Utilização de geotecnologias nos estudos socioambientais urbanos}

Em um cenário de expressiva expansão urbana no Brasil, os instrumentos de planejamento urbano se fazem necessários a fim de se criarem estratégias para o desenvolvimento das cidades em bases sustentáveis. Historicamente, o crescimento das cidades brasileiras não tem respeitado os condicionantes e vulnerabilidades ambientais do sítio urbano original, cuja consequência é o desequilíbrio ambiental decorrente da intensa pressão humana sobre os geoambientes. Em vista disso, salienta-se novamente a importância aplicada das geotecnologias como ferramenta complementar na geração de parâmetros de uso e ocupação do espaço urbano (Quadro 05). 
Geografia, geotecnologias e as novas tendências da geoinformação: indicação de estudos realizados na região Nordeste

Francisco Jonh Lennon Tavares da Silva; Dyego Freitas Rocha; Cláudia Maria Sabóia de Aquino

Quadro 05 - Estudos socioambientais urbanos com suporte de geotecnologias

\begin{tabular}{|c|c|c|}
\hline Autor (es) & Título/Recorte espacial & $\begin{array}{l}\text { Geotecnologias } \\
\text { utilizadas }\end{array}$ \\
\hline $\begin{array}{l}\text { Barreto; } \\
\text { Silva; } \\
\text { Oliveira } \\
\text { (2012). }\end{array}$ & $\begin{array}{l}\text { Análise da mineração em áreas urbanas no contexto } \\
\text { do ordenamento territorial: estudo de caso do } \\
\text { município de Jaboatão dos Guararapes, nordeste do } \\
\text { Brasil. }\end{array}$ & ArcGIS 9.0 \\
\hline $\begin{array}{l}\text { Silva; Santos } \\
\quad(2012) .\end{array}$ & $\begin{array}{l}\text { Problemática ambiental dos rios urbanos: } \\
\text { vulnerabilidades e riscos nas margens do riacho da } \\
\text { Prata na cidade de Lajedo-PE. }\end{array}$ & ArcGIS 9.3 \\
\hline $\begin{array}{l}\text { Soares; } \\
\text { Santos; } \\
\text { Cavalcanti } \\
\text { (2013). }\end{array}$ & $\begin{array}{l}\text { Problemática socioambiental urbana na nascente Pau } \\
\text { Amarelo em Garanhuns-PE. }\end{array}$ & Google Earth \\
\hline Aleixo (2014). & $\begin{array}{l}\text { Clima urbano e saúde: uma análise a partir de } \\
\text { indicadores socioambientais. }\end{array}$ & MapInfo 9.0 \\
\hline $\begin{array}{l}\text { Nascimento } \\
\text { et al. (2014). }\end{array}$ & $\begin{array}{l}\text { Análise das mudanças ambientais provocadas pela } \\
\text { expansão urbana na cidade de Mossoró-RN, através } \\
\text { do uso de técnicas de Sensoriamento Remoto. }\end{array}$ & $\begin{array}{l}\text { ERDAS imagine } \\
\quad 9.3\end{array}$ \\
\hline $\begin{array}{l}\text { Albuquerque; } \\
\text { Medeiros; } \\
\text { Souza (2015). }\end{array}$ & $\begin{array}{l}\text { Geoinformação na abordagem de problemas } \\
\text { socioambientais: aplicação do IDG no município de } \\
\text { Horizonte, estado do Ceará. }\end{array}$ & $\begin{array}{c}\text { QGis 1.6.0; } \\
\text { PostgreSQL } \\
\text { 9.0.4-1; ArcGIS } \\
9.3\end{array}$ \\
\hline
\end{tabular}

Fonte: Elaboração dos autores (2016).

Assiste-se ao apogeu de atração dos geógrafos pelas funcionalidades do Geoprocessamento, do Sensoriamento Remoto e dos princípios oferecidos pela emergente ciência da Geoinformação. Dentro desta atmosfera de recalibragem das técnicas de trabalho, os pesquisadores fazem desabrochar elaborações geocartográficas cada vez mais precisas.

Todavia, por mais avançada que esteja a moderna engenharia de hardware e software e por melhor equipados que estejam os laboratórios de Geoprocessamento, a aplicação das Geotecnologias apenas far-se-á exitosa quando consubstanciada em critérios de validação rigorosos, amparados por um contexto metodológico especificado e por uma estrutura teórico-conceitual sólida.

Nesse contexto, depreende-se que a concatenação das Geotecnologias aos estudos geográficos não pode ser praticada através de ideias desarrumadas. Sem um arcabouço bem estruturado de conceitos e princípios lógicos norteadores o discurso geográfico se fragiliza, correndo o risco de cair no empirismo puro e ingênuo (MOREIRA, 2007).

\section{CONSIDERAÇÕES FINAIS}


Geografia, geotecnologias e as novas tendências da geoinformação: indicação de estudos realizados na região Nordeste

Francisco Jonh Lennon Tavares da Silva; Dyego Freitas Rocha; Cláudia Maria Sabóia de Aquino

Ao se considerar a natureza e o contexto contemporâneo das pesquisas geográficas, as aplicações temáticas das Geotecnologias devem ser desenvolvidas em consonância com os pressupostos geográficos, pois os programas de Geoprocessamento per se não interpretam a realidade socioespacial: são os esquemas metodológicos, conceituais e categorias de análise geográficas que dão vida e significado aos produtos cartográficos.

No que tange ao conjunto de Geotecnologias disponíveis, estas estão cada vez mais interligadas. Sua aplicação aos diferentes campos do conhecimento têm se alargado. A princípio, essas tecnologias têm vasta aplicação aos temas trabalhados pelos geógrafos. Essa pluralidade temática para a qual o uso das Geotecnologias tem convergido advém de diferentes matrizes teórico-metodológicas, mormente as abordagens integrativas que procuram analisar a relação Sociedade-Natureza.

Temas como degradação ambiental, desertificação, análise ambiental em bacias hidrográficas, uso/ocupação e cobertura da terra, problemas socioambientais urbanos, dentre outros, despontam como algumas das possibilidades de aplicação das novas ferramentas de análise espacial - aplicação que vem sendo consubstanciada na abordagem sistêmica, preferencialmente.

Nessas circunstâncias, o uso crítico dos conceitos científicos, o domínio das tecnologias de trabalho, a adoção de uma linha metodológica embasada em pressupostos teóricos consistentes colocam-se como requisitos básicos para todo e qualquer estudo geográfico.

Neste prisma, o uso substantivo da Geoinformação requer uma disciplina que ofereça sustentação epistemológica, um corpo básico de teoria e métodos que sirva de suporte a uma visão sólida sobre as potencialidades e limitações das Geotecnologias. A partir deste princípio, ressalta-se que os pressupostos e princípios teórico-conceituais da ciência geográfica não devem ser esquecidos à porta dos laboratórios de Geoprocessamento.

\section{REFERÊNCIAS}

ALBUQUERQUE, E. L. S.; MEDEIROS, C. N.; GOMES, D. D. M.; CRUZ, M. L. B. SIG-WEB Ceará em mapas interativos, novas ferramentas na cartografia escolar. Revista Mercator, Fortaleza, v. 11, n. 24, p. 253-269, jan./abr. 2012.

ALBUQUERQUE, E. L. S.; MEDEIROS, C. N.; SOUZA, M. J. N. Geoinformação na abordagem de problemas socioambientais: aplicação do IDG no município de Horizonte, estado do Ceará. Revista Equador, Teresina, v. 4, n. 2, p. 128-143, 2015. 
Geografia, geotecnologias e as novas tendências da geoinformação: indicação de estudos realizados na região Nordeste

Francisco Jonh Lennon Tavares da Silva; Dyego Freitas Rocha; Cláudia Maria Sabóia de Aquino

ALBUQUERQUE, E. L. S.; SOUZA, M. J. N. Condições ambientais e socioeconômicas nas bacias hidrográficas costeiras do setor leste metropolitano de Fortaleza, estado do Ceará. Revista Brasileira de Geografia Física, Recife, v. 9, n. 1, p. 110-124, 2016.

ALEIXO, N. C. R. Clima urbano e saúde: uma análise a partir de indicadores socioambientais. Revista GeoUECE, Fortaleza, v. 3, n. 4, p. 194-2016, jan./jun. 2014.

ALVES JÚNIOR, L. R.; CÔRTES, J. B. R.; SILVA, J. R.; FERREIRA, M. E. Validação de ortomosaicos e modelos digitais de terreno utilizando fotografias obtidas com câmera digital não métrica acoplada a um VANT. Revista Brasileira de Cartografia, Rio de Janeiro, v. 7, n. 67, p. 1453-1466, nov./dez. 2015.

AMORIM, D. C. R.; SILVA, P. N. O sensoriamento remoto e suas técnicas de análise: uma comparação entre novas e velhas tecnologias, um estudo de caso sobre a tecnologia LIDAR (o mapeamento de território através das árvores). In: ENCONTRO NACIONAL DE GEOGRAFIA AGRÁRIA, 21., 2012, Uberlândia. Anais eletrônicos... Uberlândia: UFU/LAGEA, $2012 . \quad$ p. 1-12. Disponível em:

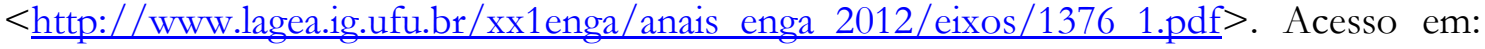
jun. 2016.

AMORIM, R. R.; OLIVEIRA, R. C. Zoneamento ambiental, subsídio ao planejamento no uso e ocupação das terras da Costa do Descobrimento. Revista Mercator, Fortaleza, v. 12, n. 29, p. 211-231, set./dez. 2013.

AQUINO, C. M. S.; ALMEIDA, J. A. P.; OLIVEIRA, J. G. B. Aspectos socioambientais do núcleo de desertificação de São Raimundo Nonato/Piauí. Revista Mercator, Fortaleza, v. 11, n. 26, p. 171-182, set./dez. 2012.

AQUINO, C. M. S.; VALLADARES, G. S. Geografia, geotecnologias e planejamento ambiental. Revista Geografia, Londrina, v. 22, n.1, p. 117-138, jan./abr. 2013.

ARAÚJO, F. A. S. Geomorfologia aplicada à fragilidade e ao zoneamento ambiental de Caxias-MA. 2012. 185 f. Tese (Doutorado em Geografia) - Universidade Estadual Paulista (UNESP), Presidente Prudente, 2012.

BAKER, V. R. Introduction: regional landforms analysis. In: SHORT, N. M.; BLAIR, R. W. (Org.). Geomorphology from space: a global overview of regional landforms. Washington, DC: NASA, 1986.

BARBOSA NETO, M. V.; SILVA, C. B.; ARAÚJO FILHO, J. C.; ARAÚJO, M. S. B.; BRAGA, R. A. P. Uso da terra na bacia hidrográfica do rio Natuba, Pernambuco. Revista Brasileira de Geografia Física, Recife, v. 4, n. 5, p. 961-973, 2011.

BARRETO, E. P.; SILVA, C. M. M.; OLIVEIRA, P. F. P. Análise da mineração em áreas urbanas no contexto do ordenamento territorial: estudo de caso do município de Jaboatão dos Guararapes, Nordeste do Brasil. Revista Brasileira de Geografia Física, Recife, v. 5, n. 5, p. 1002-1018, 2012.

BEZERRA, J. M.; SILVA, P. C. M.; MORAIS, C. T. S. L.; BATISTA, R. O. Utilização de geotecnologias na determinação de áreas susceptíveis à desertificação no estado do Rio 
Geografia, geotecnologias e as novas tendências da geoinformação: indicação de estudos realizados na região Nordeste

Francisco Jonh Lennon Tavares da Silva; Dyego Freitas Rocha; Cláudia Maria Sabóia de Aquino

Grande do Norte. Revista Brasileira de Geografia Física, Recife, v. 4, n. 3, p. 543-561, 2011.

BRITTO, F. B.; MENEZES NETO, E. L.; AGUIAR NETTO, A. O.; REGO, N. A. C. Sustentabilidade hídrica da sub-bacia do rio Sangradouro, Sergipe. Revista Brasileira de Geografia Física, Recife, v. 7, n. 1, p. 155-164, 2014.

CABRAL, C. J.; SILVA, W. F.; GIRÃO, O. Impactos ambientais derivados do uso e ocupação da linha de costa em trechos das praias de Pau Amarelo e Maria Farinha município de Paulista/PE: estudo preliminar. Revista da Casa da Geografia de Sobral, Sobral, v. 16, n. 1, p. 74-88, 2014.

CARDOSO, J. A.; AQUINO, C. M. S. Análise dos usos e cobertura das terras das microbacias hidrográficas do riacho do Roncador - Timon (MA): subsídios ao planejamento ambiental. Boletim Campineiro de Geografia, Campinas, v. 3, n. 2, p. 305307, 2013.

CHRISTOFOLETTI, A. Modelagem de sistemas ambientais. São Paulo: Edgard Blücher, 1999.

CIRILO, J. A.; ALVES, F. H. B.; SILVA, L. A. C.; CAMPOS, J. H. A. L. Suporte de informações georreferenciadas de alta resolução para implantação de infraestrutura e planejamento territorial. Revista Brasileira de Geografia Física, Recife, v. 7, n. 4, p. 755$763,2014$.

COSTA, L. R. F.; OLIVEIRA, V. P. V. Os sistemas ambientais e a análise ambiental no contexto semiárido: o caso da sub-bacia hidrográfica do riacho Santa Rosa. Revista Equador, Teresina, v. 4, n. 2, p. 56-76, 2015.

FERREIRA, M. C. Considerações teórico-metodológicas sobre as origens e a inserção do sistema de informação geográfica na geografia. In: VITTE, A. C. (Org.). Contribuições à história e à epistemologia da Geografia. Rio de Janeiro: Bertrand Brasil, 2006. p. 101125.

FLORENZANO, T. G. Cartografia. In: tecnologias atuais. São Paulo: Oficina de Textos, 2008.

(Org.). Geomorfologia: conceitos e

GALVANIN, E. A. S.; DAL POZ, A. P. Sistema lidar e métodos de interpolação de dados. Revista de Geografia, Recife, v. 30, n. 1, p. 91-102, 2013.

GIROTTO, E. D.; PELEGRINA, M. A. Utilização da infraestrutura de dados espaciais em sala de aula: o caso do i3geo. Revista de Geografia, Recife, v. 27, n. 3, p. 73-85, 2010.

GOMES, D. D. M.; MEDEIROS, C. N.; ALBUQUERQUE, E. L. S.; DUARTE, C. R.; VERÍSSIMO, C. U. V. Geotecnologias aplicadas ao diagnóstico geoambiental da bacia hidrográfica do rio Jaibaras no semiárido cearense. Revista Brasileira de Cartografia, Rio de Janeiro, v. 65, n. 1, p. 35-52, 2013.

IPECE. Instituto de Pesquisa e Estratégia Econômica do Ceará. Ceará em Mapas Interativos. Disponível em: <http://www.ipece.ce.gov.br/categoria5/ceara-em-mapasinterativos >. Acesso em: jun. 2016. 
Geografia, geotecnologias e as novas tendências da geoinformação: indicação de estudos realizados na região Nordeste

Francisco Jonh Lennon Tavares da Silva; Dyego Freitas Rocha; Cláudia Maria Sabóia de Aquino

IPPOLITI, G. A.; EPIPHANIO, J. C. N.; SHIMABUKURO, Y. E. Utilização de Sensoriamento remoto na previsão de área a ser plantada com culturas de verão em três municípios do Estado de São Paulo. In: SIMPÓSIO BRASILEIRO DE SENSORIAMENTO REMOTO, 9., 1998, Santos. Anais eletrônicos... São José dos Campos: Instituto Nacional de Pesquisas Espaciais - INPE, 1998. p. 25-37. Disponível em: $<$ http://marte.sid.inpe.br/col/sid.inpe.br/deise/1999/02.05.10.00/doc/3 1080.pdf $>$.

Acesso em: jun. 2016.

KERSKI, J. J. Geo-awareness, Geo-enablement, Geotechnologies, Citizen Science, and Storytelling: Geography on the World Stage. Geography Compass, v. 9, n. 1, p. 14-26, 2015.

LUZ C. C.; ANTUNES A. F. B. Validação da tecnologia VANT na atualização de bases de dados cartográficos geológicos - estudo de caso: sistema cárstico do rio João Rodrigues. Revista Brasileira de Cartografia, Rio de Janeiro, n. 67, v. 7, p. 1439-1452, 2015.

MELO, J. A. B.; LIMA, E. R. V. Uso da terra, vulnerabilidade e subsídios ao ordenamento territorial em microbacia. Revista Mercator, Fortaleza, v. 11, n. 24, p. 127-148, jan./abr. 2012.

MOREIRA, R. Pensar e ser em Geografia: ensaios de história, epistemologia e ontologia do espaço geográfico. São Paulo: Contexto, 2007.

NASCIMENTO, F. C. A.; ARAÚJO, F. R. C. D.; SANTOS, C. A. C.; SANTOS, E. G. Análise das mudanças ambientais provocadas pela expansão urbana na cidade de Mossoró$\mathrm{RN}$, através do uso de técnicas de sensoriamento remoto. Revista Brasileira de Geografia Física, Recife, v. 7, n. 4, p. 636-642, 2014.

NASCIMENTO, F. R. Degradação ambiental e desertificação no nordeste brasileiro: o contexto da bacia hidrográfica do rio Acaraú/Ceará. 2006. 340 f. Tese (Doutorado em Geografia) - Instituto de Geociências, Universidade Federal Fluminense, Niterói, 2006.

PIMENTA, F. M.; LANDAU, E. C.; HIRSCH, A.; GUIMARÃES, D. P. Servidores de mapas: programação para disponibilizar dados geográficos multidisciplinares utilizando tecnologias livres. Brasília: EMBRAPA, 2012.

QUEIROZ, P. H. B.; SALES, M. C. L.; SILVA, J. M. O. Indicadores morfométricos como subsídio ao planejamento ambiental em um setor do médio curso da bacia hidrográfica do rio Pacoti - CE. Revista Equador, Teresina, v. 3, n. 1, p. 03-24, jan./jun. 2014.

ROSA, R. Geotecnologias na Geografia aplicada. Revista do Departamento de Geografia, São Paulo, v. 16, p. 81-90, 2005.

Análise espacial em geografia. Revista da ANPEGE, Dourados-MS, v. 7, n. 1, número especial, p. 275-289, out. 2011.

SÁ, I. B.; CUNHA, T. F.; TAURA, T. A.; DRUMOND, M. A. Mapeamento da desertificação da mesorregião sul do Ceará com base na cobertura vegetal e nas classes de solos. Revista Brasileira de Geografia Física, Recife, v. 7, n. 3, p. 572-583, 2014. 
Geografia, geotecnologias e as novas tendências da geoinformação: indicação de estudos realizados na região Nordeste

Francisco Jonh Lennon Tavares da Silva; Dyego Freitas Rocha; Cláudia Maria Sabóia de Aquino

SANTOS, F. A. Mapeamento das unidades geoambientais e estudo do risco de degradação/desertificação nos municípios de Castelo do Piauí e Juazeiro do Piauí. 2015. 187 f. Dissertação (Mestrado em Geografia) - Universidade Federal do Piauí, Teresina, 2015.

SILVA, C. B.; ARAÚJO, M. S. B.; ARAÚJO FILHO, J. C.; SCHULZE, S. M. B. B. Delimitação de geoambientes numa bacia hidrográfica na zona da mata de Pernambuco. Revista Brasileira de Geografia Física, Recife, v. 5, n. 5, p. 1259-1274, 2012.

SILVA, E. R. A. C.; MELO, J. G. S.; GALVÍNCIO, J. D. Identificação das áreas susceptíveis a processos de desertificação no médio trecho da bacia do Ipojuca - PE através do mapeamento do estresse hídrico da vegetação e da estimativa do índice de aridez. Revista Brasileira de Geografia Física, Recife, v. 4, n. 3, p. 629-649, 2011.

SILVA, J. C. F.; SANTOS, C. C. Problemática ambiental dos rios urbanos: vulnerabilidades e riscos nas margens do Riacho da Prata na cidade de Lajedo-PE. Revista Brasileira de Geografia Física, Recife, v. 5, n. 3, p. 488-508, 2012.

SCHIMALESKY, V.; CENTENO, J. A. S. Avaliação da qualidade da informação altimétrica derivada da varredura a laser em uma região coberta por vegetação: estudo de caso. Revista Floresta, Curitiba, v. 38, n. 4, p. 597-606, out./dez. 2008.

SCHIMIGUEL, J.; BARANAUSKAS, M. C. C.; MEDEIROS, C. B. Usabilidade de aplicações SIG WEB na perspectiva do usuário: um estudo de caso. In: SIMPÓSIO BRASILEIRO DE GEOINFORMÁTICA, 7., 2005, Campos do Jordão. Anais eletrônicos... São José dos Campos: Instituto Nacional de Pesquisas Espaciais - INPE, p. 262-268. Disponível em: <http://mtcm16c.sid.inpe.br/col/dpi.inpe.br/geoinfo@,80/2006/07.11.12.45/doc/P44.pdf>. Acesso em: jun. 2016.

SOARES, A. B.; SANTOS, C. C.; CAVALCANTI, M. A. Problemática socioambiental urbana na nascente Pau Amarelo em Garanhuns-PE. Revista Brasileira de Geografia Física, Recife, v. 6, n. 5, p. 1140-1157, 2013.

SOUSA, R. S.; MOURA, P. E. F.; SILVA, R. S. F. Diagnóstico socioambiental da ocupação desordenada do campo de dunas na comunidade Iguape/Aquiraz-CE. Revista Equador, Teresina, v. 4, n. 4, p. 21-35, jul./dez., 2015.

ZAIDAN, R. T.; XAVIER DA SILVA, J. Geoprocessamento aplicado ao zoneamento de áreas com necessidade de proteção: o caso do Parque Estadual do Ibitipoca - MG. In: XAVIER DA SILVA, J.; ZAIDAN, R. T. (Org.). Geoprocessamento e Análise Ambiental: aplicações. 2. ed. Rio de Janeiro: Bertrand Brasil, 2007. 